\title{
HUMAN RESOURCE POLICIES AND WORK CULTURE: A CASE OF STARBUCKS
}

\author{
Shinta Dewi Sugiharti Tikson \\ Lecturer Department of Management, Faculty of Economics and Business \\ Universitas Hasanuddin \\ shintatikson@gmail.com \\ Nurdjanah Hamid \\ Lecturer Department of Management, Faculty of Economics and Business \\ Universitas Hasanuddin \\ nununghamid17@gmail.com
}

\begin{abstract}
This paper discusses the human resource management policies and work culture at Starbucks. Starbucks views their employees as company assets that must be managed correctly in order to maintain the most valuable human resources in the business. This company also understands the relationship between positive human resource management policies and work culture and employee motivation. Therefore, the company takes great care in selecting the right kind of people and make an effort to retain them. For that reason, the company's human resource policies reflects its commitment on its employees.
\end{abstract}

Keywords: Human resource policies and practice, work culture, Starbucks, employee motivation

\section{INTRODUCTION}

Starbucks was established in Seattle in 1971, and become one of the best known and fastest growing companies in the world (IBS Center for Management Research, 2005). The company grew slowly but surely and expanded rapidly in the late 1980s and the 1990s. By the early 2000s, there were nearly 9,000 Starbucks outlets across the world.

Starbucks entered the $21^{\text {st }}$ century with the goal of increasing shareholder value through consolidating its position in mature markets and improving margins by increasing the volume sales of premium coffee. To this end, the strategic questions facing management is how to develop their premium product - StarbucksCoffee - into the company's flagship brand in key markets around the world. The premium coffee market is growing and Starbucks wants to take advantage of the superior profit margins offered in this sector.

According to Interbrand (Best Global Brand Rankings, 2016) Starbucks is positioned 64 globally amongst other premium brands. Starbucks' growth is the result of an ambitious five- 


\section{Jurnal Bisnis, Manajemen dan Informatika}

year plan which was announced in 2014. This plan includes global expansion, new retail offerings, and innovation demonstrated through new products and experiences. Starbucks continues to grow globally, with the goal of increasing its store count to 30,000 by 2019 . Starbucks is committed to delivering the innovation, execution, and elevated customer experience necessary to remain one of the world's most trusted consumer brands.

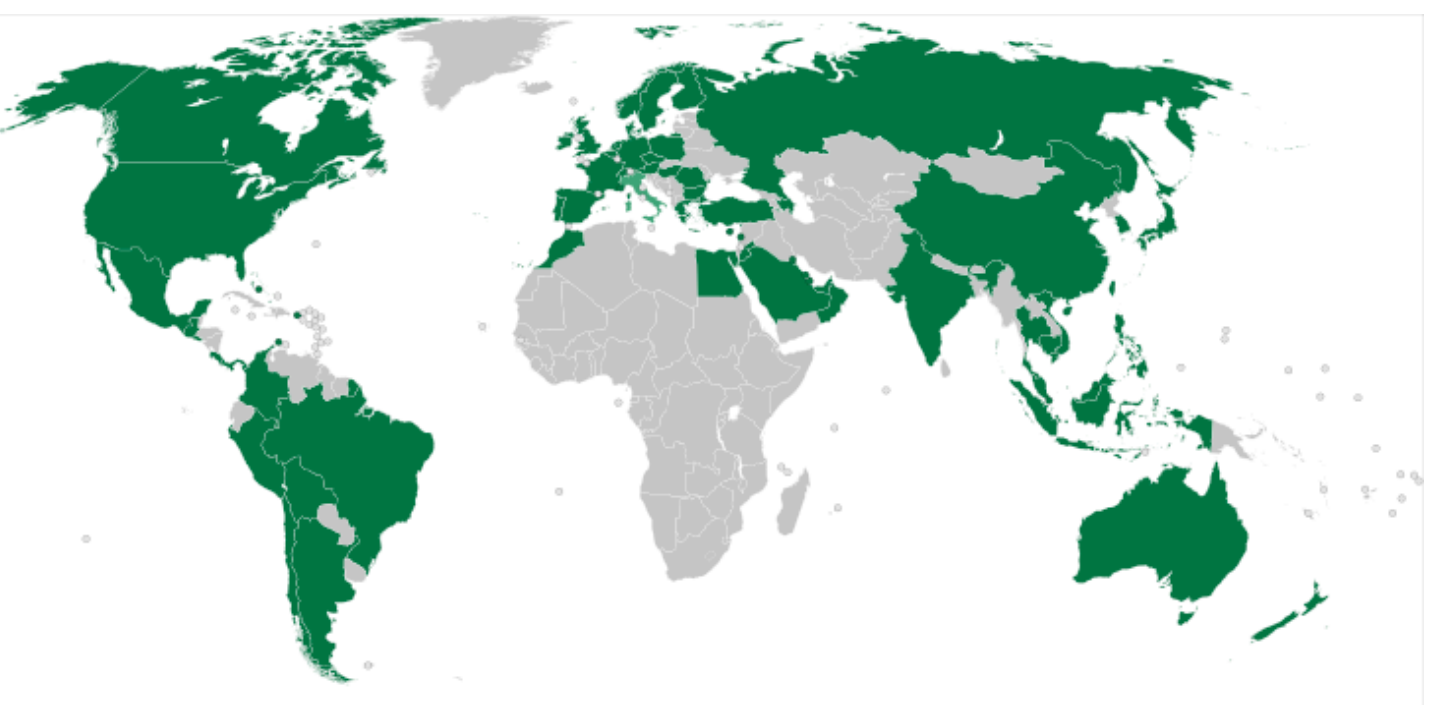

Figure 1: Starbucks Locations Around the Globe

Source:IBS Center for Management Research

Starbucks has taken a risk adverse strategy in expanding its market share around the globe and through license agreements in mature markets, Starbucks can take advantage of already established production and distribution networks. This can be seen in figure 1 where Starbucks locations around the globe has increased significantly. Today, Starbucks is the largest coffeehouse company in the world, with 23,571 retail locations as of the first quarter of 2016.

\section{Number of Starbucks Stores Globally}

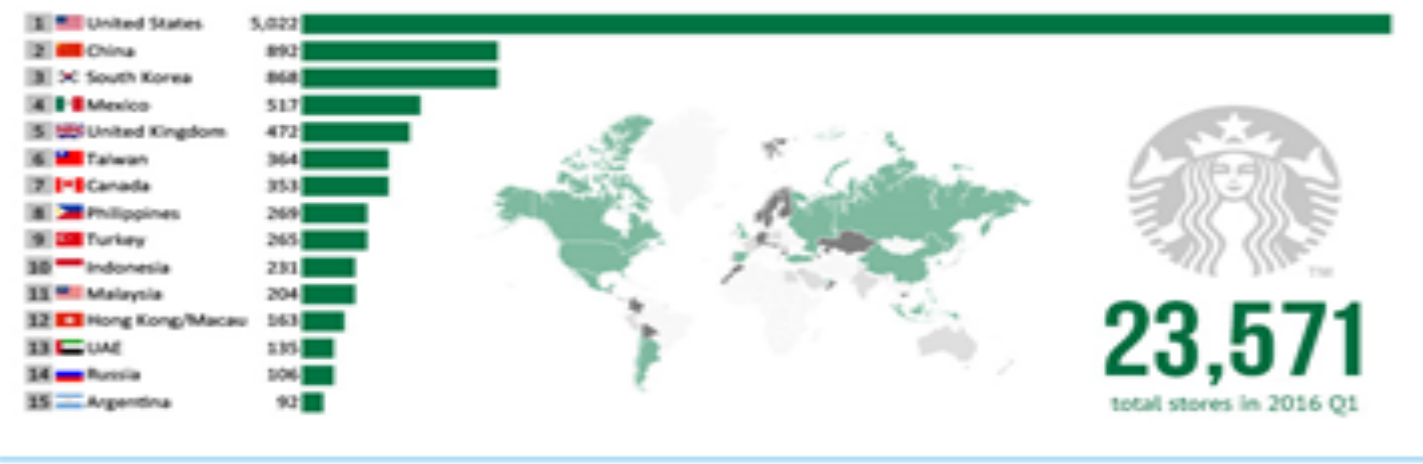

Figure 2: Number of Starbucks Stores Worldwide 2016

Source:www.knoema.com 
It was widely believed that the company's success and rapid growth could be attributed largely to its committed and motivated workforce. For that reason, this case discusses the human resource management policies and work culture at Starbucks. Also, to understand the relationship between positive human resource management policies and work culture and employee motivation.

\section{DISCUSSION AND LITERATURE REVIEW}

It has been expected to those familiar with the company's human resources management policies and work culture when in January 2005 Fortune magazine placed Starbucks Coffee Company second among the largest companies for "Best Companies to Work For. "Starbucks stood out for its employee-friendly policies and supportive work culture. The company was especially noted for the extension of its benefits program to part-time workers - something not many other companies offered. As pointed out by IBS Center for Management Research (2005) Starbucks cared about its employees and was one of the few companies in the retail sector to provide generous benefits to both full time workers as well as part timers. This ensured that employees remained motivated and were among the most productive in the industry. As a result, the company had a relatively low employee turnover. The equity theory of motivation supports this practice since people are strongly motivated when they perceive fair treatment in the amount of rewards an employer allocates, and it also resulted in lower rate of turnovers (Dessler, 2013). Furthermore, Noe et al. (2010) argued that to increase company's competitiveness, companies must invest not only in new technology and promoting quality throughout the organization but also invest in state-of-the-art satffing, training, and compensation practices.

Dessler (2013) continue by arguing that a company's compensation plan should first advance its stratgeic aims. This means aligning reward strategy by creating compensation package including wages, incentives, and benefits that produces employee behaviors the company needs to support and achieve its competitive advantage. Analysts said that, in the light of its ambitious expansion program, Starbucks' generous human resource policies is an exceptional strategic plan, as they kept the turnover low and provided a supply of experienced employees to support expansion. In expanding Starbucks Coffee, it must focuses on human resources. Emphasis on the productive service, such as skills, knowledge, performance and loyalty of employee to the 
company will generate a stable growth environment. This description of human capital further explained by Noe et al. (2010) employees in today's organizations are not interchangeable nor easily replaced because they are the source of the company's success or failure. Employees should be encouraged to put forward propositions to improve processes but Starbucks should concentrate on enhancing employee motivation over technical performance, as there is little potential for growth through technological innovation.

The climate of rapid change through globalization and renewed corporate goals underpin a need to communicate values. Customers and employees respond to the company's values. Employees can be motivated and committed to the company direction if the company values its employees. As for customers, they identify company values conveyed in brand names, reputation and technology, in the process of committing to it. Beamish and Goerzen (2000) state that brands usually have hundreds of years of heritage behind them and had become such a basic part of everyday life that consumers will be loyal to them. Consumers prefer and are willing to pay for known branded products compared to unbranded or unknown brands. Brand and company reputations are valuable resources that depend on employees, customers, investors and governments (Grant, 2005).

\section{Human Resources Management at Starbucks}

In the early $2000 \mathrm{~s}$, Starbucks faced the challenge of finding and retaining the right number and kind of employees to ensure its future growth. Starbucks realized early on that motivated and committed human resources were the key to the success of a retail business. Therefore, the company took great care in selecting the right kind of people and made an effort to retain them. If an organization's human resource policies are designed properly, the selection practices will identify competent candidates and accurately match them to the job and the organization (Robbins \& Judge, 2013). Further, Noe et al. (2010) also point out decisions such as whom to hire, what to pay, what training to offer, and how to evaluate employee performance directly affect employees' motivation and ability to provide goods and services that customer value. As a result, the company's human resource policies reflected its commitment to its employees.

Starbucks relied on its baristas and other frontline staff to a great extent in creating the 'Starbucks Experience' which differentiated it from competitors. Therefore, the company paid considerable attention to the kind of people it recruited. Starbucks' recruitment motto was "To have the right people hiring the right people. "DeCenzo and Robbins (2010) argued that 
companies today prefer employee involvement which includes delegation, participative management, work teams, goal setting, and employer training.

Starbucks hired people for qualities like adaptability, dependability and the ability to work in a team. The company often stated the qualities that it looked for in employees upfront in its job postings, which allowed prospective employees to self-select themselves to a certain extent. Similarly argued by DeCenzo and Robbins (2010) management must ensure that those to whom they make offers can see the job's compatibility with their personality and goals. If the candidate sees that the culture or "brand" is still a good fit with his or her image, the chances of a successful hire increase.

Research shows that individual's perception of the company's attractiveness is important. In addition, candidates have their own expectations where they believe their goals can be achieved (DeCenzo \& Robbins, 2010). Having selected the right kind of people, Starbucks invested in training them in the skills they would require performing their jobs efficiently. Starbucks was one of the few retail companies to invest considerably in employee training and provide comprehensive training to all classes of employees, including part-timers.

\section{Public Policy and Internal Standards at Starbucks}

Starbucks believes it has the responsibility to advocate both internal and public policies that support the health of its business, its partners (employees) and the communities it serves. As Armstrong (2006) points out human resource policies are guidelines defining company values, principles and strategies that should be applied and implemented in specific human resource management areas. For Starbucks, its policies demonstrate its commitment to being a responsible business which range from global ethical business standards, choosing the best coffee supplier, and ensuring the best possible workplace. This standard must be consistent with its mission: "to inspire and nurture the human spirit - one person, one cup and one neighborhood at a time."

Additionally, Robbins and Judge (2013) state that an organization's human resource policies and practices create important forces that shape employee behavior and attitudes. In line with this theory is Starbucks core values which require its policies compliance with the law, as well as ethical conduct. The following are some of Starbucks' company policies taken from Starbucks' Business Ethics and Compliance: Standards of Business Conduct handbook. 
- Anti-Retaliation Policy. Starbucks does not tolerate retaliation against or the victimization of any partner who raises concerns or questions regarding a potential violation of the Standards of Business Conduct or any Starbucks policy that he or she reasonably believes to have occurred.

- Hiring Policy. Consistent with Starbucks Global Human Rights Standard, Starbucks promotes equal opportunity in its hiring practices, makes recruiting decisions based solely on job-related criteria and does not use forced labor. According to Robbins and Judge (2013) if properly designed, an organization's selection practices will identify competent candidates and accurately match them to the job and the organization.

- Workplace Environment. At Starbucks people treat each other with respect and dignity. This means that all partners are entitled to work in an environment that is free of harassment, bullying and discrimination.

- Diversity. Starbucks actively creates and promotes an environment that is inclusive of all people and their unique abilities, strengths and differences, and promotes diversity as a strategic and competitive business advantage for the company.

- Workplace Health, Safety and Security. Partners are expected to follow all safety rules and practices; cooperate with officials who enforce these rules and practices; take necessary steps to protect themselves and other partners; attend required safety training; and report immediately all accidents, injuries and unsafe practices or conditions. In order to enhance workplace security, partners should be familiar with and follow any work safety information and training provided to them.

- Starbucks Quality and Customer Protection. Starbucks commitment to quality means that they take steps to protect their customers' health and safety.

- Substance Abuse and Weapons. Starbucks has strict standards regarding substance abuse and weapons. Partners are not permitted to use or possess alcoholic beverages on company property, except where alcohol is specifically permitted at a Starbuckssponsored social event.

Partners also may not use or possess illegal drugs or controlled substances on Starbucks property or while they are engaged in any job-related activity. Partners may not report to work under the influence of alcohol, illegal drugs or controlled substances.

Partners may not have or possess any weapon while in a Starbucks store, plant or on other Starbucks property. It is essential for partners to understand and follow the policy 
because Starbucks takes its rules regarding workplace health, safety and security very seriously.

- Wage and Hour Rules. Starbucks is committed to following all applicable wage and hour laws and regulations. To help ensure that all work performed for Starbucks is compensated correctly, partners compensated on the basis of hours worked must report and record time accurately in accordance with established local procedure.

- Community Involvement. Starbucks is committed to a role of environmental leadership in all facets of its business.

$\checkmark$ Understanding environmental issues and sharing information with our partners

$\checkmark$ Developing innovative and flexible solutions to bring about change

$\checkmark$ Striving to buy, sell and use environmentally friendly products

$\checkmark$ Recognizing that fiscal responsibility is essential to our environmental future

$\checkmark$ Instilling environmental responsibility as a corporate value

$\checkmark$ Measuring and monitoring our progress for each project

$\checkmark$ Encouraging all partners to share in our mission

The standards and policies of Starbucks may not all applicable nor is it a comprehensive explanation due to the different laws that are applicable in each Starbucks stores globally. Since countries have different laws, human resource managers need to understand societal issues, such as status, that might affect operations in another country (DeCenzo \& Robbins, 2010). However, at Starbucks, the partners are involved in formulating the best policy for them, and each suggestions or ideas are respected by top management. Starbucks even wants every employee to join in making and developing plans, then achieving their goals all together. As a result, the policies and principles are communicated between all staffs, and there is no limitation in employees' personal opinions. This practice is in line with a research done by The Great Place to Work Institute (2008) that finds the best management practice for creating a work culture that achieves superior performance is when employees trust the people they work for, have pride in what they do, and enjoy the people they work with (Collins, 2009).

\section{Work Culture at Starbucks}

According to an article from Panmore Institute (2015) Starbucks has an organizational culture that relates with the company's strategies for successful brand development and global expansion. Starbucks Coffee's organizational culture has a number of key characteristics. The 
Jurnal Bisnis, Manajemen dan Informatika

combination of these characteristics is unique to the company. The company describes its organizational culture as a culture of belonging, inclusion and diversity. In this regard, the main features of Starbucks' organizational culture are servant leadership (“employees first"); relationship-driven approach; collaboration and communication; openness; and inclusion and diversity.

Servant Leadership. Starbucks has a servant leadership approach, which significantly characterizes the company's organizational culture. In this approach, leaders, managers and supervisors emphasize support for subordinates to ensure that everyone grows in the company. This feature of Starbucks' organizational culture translates to the employees-first approach. The company highlights the importance of caring for employees. Former Starbucks President Howard Behar developed this feature of the firm's organizational culture because he believed that employees who are cared for are the ones who care about customers.

Relationship-driven Approach. Starbucks also has an organizational culture that supports warm and friendly relationships. For instance, at Starbucks cafés, baristas exhibit warm friendly bonds with each other. This feature of the company's organizational culture extends to customers, who are also treated with warmth. Through emphasis on relationships, Starbucks develops the coffee culture that drives consumer demand for the company's specialty coffee products.

Collaboration and Communication. The organizational culture of Starbucks encourages collaborative efforts through effective communication. At the cafés, baristas clearly communicate with each other to fulfill orders. Also, they collaborate as teams to make the order fulfillment process efficient. Thus, Starbucks' organizational culture supports efficiency in business processes, which contributes to quality of service, customer experience, and business cost-effectiveness.

Openness. Openness is another major characteristic of Starbucks Coffee's organizational culture. Initially, employees had a culture of fear to speak up to their superiors. To address this issue, former Starbucks President Behar introduced open forums to encourage employees to ask questions and communicate with superiors. A culture of openness developed. Through this feature of its organizational culture, Starbucks empowers employees and facilitates innovation. Inclusion and Diversity. Starbucks has an anti-discrimination policy that shapes its organizational culture. This policy prohibits any form of discrimination based on gender, race, ethnicity, sexual orientation, religion, age, cultural backgrounds, life experiences, thoughts and ideas. Through this feature of the organizational culture, Starbucks facilitates sharing and 
rapport among employees, as well as innovation based on diverse ideas. This aspect of the company's organizational culture also makes customers feel welcome at Starbucks cafés.

Starbucks has gone through significant changes in its organizational culture. These changes are based on issues and problems leaders like Howard Schultz and Howard Behar identified. Organization's culture controls the way employees perceive and respond to the people and situation around them and how they use this information to make decisions (George and Jones, 2012). As a way of enhancing business performance, Starbucks instituted reforms in its organizational culture. Today, the company's organizational culture is a distinct characteristic that builds competitive advantage and develops a consumer population of loyal Starbucks fans. Robbins and Judge (2013) define organizational culture as a system of shared meaning held by members that distinguishes the organization from other organizations.

\section{Employee Motivation at Starbucks}

Motivation is important in any organization because it has a strong correlation on employee work behavior. Additionally, George and Jones (2012) explain motivation involves psychological forces within a person, therefore determine the direction of that person's behavior in an organization, effort level, and persistence in the face of obstacles. In many cases, money usually has a big effect to work motivation. However, in today business, motivation goes beyond money itself. Starbucks, for instance, partners (employees) receive stock options, full health care benefits, and extensive training. Other factors that are essential to improving employee motivation is the working environment or relationship between employees and managers.

Moreover, the partners who work over 20 hours a week are entitled for benefits. Starbucks also thinks that debt financing is not the best choice, thus it chose allocate stock dividend to all employees with a free scrip issue. By this policy, the employees can get benefits from the dividends of company. Because of this, they have the same goal; in other words, they are motivated to increase the sales to earn more profits.

The chief executive officer of Starbucks corporation, Howard Schultz, considers that the tip of success in Starbucks is not coffee but employees. Constantly accumulating the working experience of employees and providing chances of promotion for partners is the way to operate sustainability. He firmly believes that the spirit of Starbucks is employees and feels honored about the value of Starbucks employees. For this reason, it is necessary to have a perfect education and training policy for better performance in a company (Michelli, 2007). Starbucks 
offers an interactive structure that makes employees learn amongst themselves in their job; hence they can motivate partners to satisfy themselves then achieving a new level of performance.

\section{CONCLUSION}

Starbucks core value is its employees because they are the most important asset. A culture of respect to employees and well-developed environment have lead Starbucks to produce the best working quality for customers and an increase in profits.

From a small retail coffee shop in Seattle, Starbucks successfully caught global attention and offers quality coffee for coffee lovers around the world. Today, it is not only one of the fastest growing corporation, but also an outstanding business model with lower employee turnover rate and higher profit performance. Based on Starbucks' case, it shows that good company policy and employee motivation is the key factor of a company success. All employees, including parttimers, have a voice at Starbucks which is emotionally rewarding and resulted in high motivation and personal satisfaction. In addition, good relationship between managers and employees is key in maintaining high quality performance.

\section{REFERENCES}

Armstrong, M. (2006). A handbook of human resource management practice. $10^{\text {th }}$ ed. Kogan Page, London.

Beamish, PW \& $\underline{\text { Goerzen, }}$ A. (2000). The Global Branding of Stella Artois. Ivey 9B00A019.

Collins, D. (2009). Essentials of business ethics: creating an organization of high integrity and superior performance. John Wiley \& Sons, New Jersey.

Dessler, G. (2013) Human resource management. 13th ed. Prentice Hall, U.S.A.

Free online research papers, Starbucks Corporation: Case Study in Motivation and

Teamwork. [Accessed 22/9/2016]Retrieved from

\section{http://www.freeonlineresearchpapers.com/starbucks-case-study}

George, JM \& Jones, GR. (2012). Understanding and managing organizational behavior. $6^{\text {th }}$ edn. Prentice Hall, New Jersey.

Grant, RM. (2005). Contemporary Strategy Analysis, 5th ed. Blackwell, Massachusetts.

IBS Center for Management Research. 2005. Starbucks' human resource management policies and the growth challenge. [Accessed 12/9/2016] Retrieved from 
http://www.icmrindia.org/casestudies/catalogue/Human Resource and Organization Behavior/HROB068.htm

Interbrand 2016 Rankings. [Accessed 19/4/2017] Retrieved fromhttp://interbrand.com/bestbrands/best-global-brands/2016/ranking/starbucks/

Michelli, JA. (2007). The Starbucks' experience. McGraw-Hill.

Noe, RA et al. 2011. Fundamentals of human resource management. 4th ed. McGraw-Hill, New York.

Panmore Institute Business Management. 2015. Starbucks Coffee Company’s organizational culture. [Accessed 22/9/2016] Retrieved from http://panmore.com/starbucks-coffeecompany-organizational-culture

Robbins, SP \& Judge, TA. (2013). Organizational behavior. $15^{\text {th }}$ ed. Prentice Hall, USA. Starbucks' Business Ethics and Compliance: Standards of Business Conduct handbook.

[Accessed 12/9/2016] Retrieved from https://BusinessConduct.EAWebline.com www.starbucks.ph[Accessed 10/9/2016] 